\title{
CHARACTERISTICS OF THE ELDERLY POPULATION ADMITTED TO A PORTUGUESE ACUTE PSYCHIATRY UNIT
}

\author{
V. Henriques 1 , A. Carapucinha1, A. Barcelos ${ }^{1}$, A. B. Medeiros ${ }^{1}$, C. Miranda1, C. Fernandes Santos ${ }^{1}$, F. \\ Fernandes Martins', M. Bernardo', N. Descalço', P. Casimiro1, T. Mendonça', F. Gonçalves'1 \\ ${ }_{1}^{1}$ Psychiatry and Mental Health Department, Hospital Garcia de Orta, EPE - Almada, Portugal
}

\section{Background}

- In recent years and due to the progressive aging of the population, the number of patients over 65 who needed psychiatric care has increased ${ }^{1}$. Currently, the elderly population represents a significant proportion of patients observed in clinical practice, which demonstrates the importance of the study of this group of patients.

\section{Objectives}

- To carry out a clinical and sociodemographic characterization of the elderly population admitted to a Portuguese acute psychiatry unit.

\section{Material and Methods}

- An observational descriptive study was carried out on a sample of patients aged 65 years and over admitted to the Acute Psychiatry Unit of the Hospital Garcia de Orta (Portugal) between 01/01/2016 and 31/12/2017. Case records were retrospectively consulted, analyzing sociodemographic and clinical characteristics and the main differences with respect to the younger population admitted in the same period of time.

Patients admitted to the Acute Psychiatry Unit

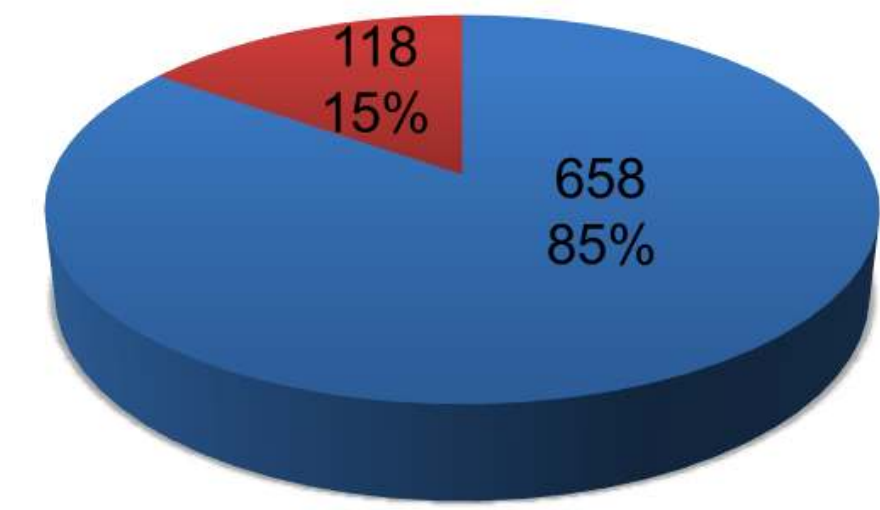

- $<65$ years old $\quad>=65$ years old

Figure 1: Number of patients admitted to the Acute Psychiatry Unit of the Hospital Garcia de Orta between 01/01/2016 and 31/12/2017.

\section{Results}

A total of 776 admissions were analyzed, of which 118 (15\%) corresponded to the study population (Figure 1). The mean age was 72 years and $59 \%$ of the patients were female. Compared to the younger population, the elderly population had a longer mean length of hospitalization (29.2 versus 21 days) and a higher number of medical comorbidities (Table 1). Also, compulsory admissions were fewer in this group of patients (25\% versus $38 \%$ ). In terms of diagnosis, the most frequent reasons for admission were affective disorders - Bipolar Disorder and Major Depressive Disorder.

\section{Conclusions}

The elderly population presented distinct characteristics compared to the younger population. We highlight the higher prevalence of medical comorbidities, which may explain the prolonged hospitalization times ${ }^{2,3}$. Perhaps a better integration and communication between medicine and psychiatry could lead to better management of underlying medical problems and improved rehabilitation 4 . Finally, it is important to continue to improve our knowledge regarding this particular population in order to improve the quality of health care.

Table 1: Characteristics of the patients admitted to the Acute Psychiatry Unit of the Hospital Garcia de Orta between 01/01/2016 and 31/12/2017.

\begin{tabular}{|c|c|c|c|}
\hline $\begin{array}{c}\text { Age of the } \\
\text { patients }\end{array}$ & $\begin{array}{c}\text { Number of } \\
\text { patients }\end{array}$ & $\begin{array}{c}\text { Mean length } \\
\text { of } \\
\text { hospitalization }\end{array}$ & $\begin{array}{c}\text { Medical } \\
\text { comorbidities }\end{array}$ \\
\hline $\begin{array}{c}>65 \text { years } \\
\text { old }\end{array}$ & 118 patients & 29,2 days & $\begin{array}{c}94 \text { patients } \\
(80 \%)\end{array}$ \\
\hline$<65$ years old & 658 patients & 21 days & $\begin{array}{c}306 \text { patients } \\
(47 \%)\end{array}$ \\
\hline
\end{tabular}

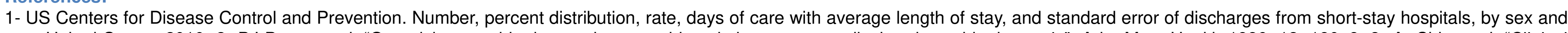

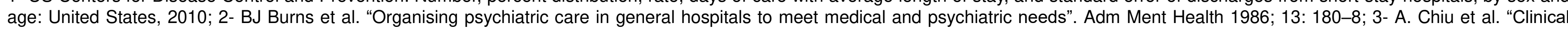

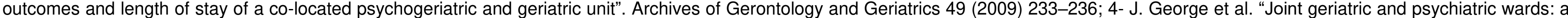
review of the literature". Age and Ageing 2011; 40: 543-548. 